Research Article

Human and Medical Genetics

\title{
FABP4 and omentin-1 gene expression in epicardial adipose tissue from coronary artery disease patients
}

\author{
Valentina V. Miroshnikova ${ }^{1,2}$ (D), Ekaterina A. Polyakova ${ }^{1}$, Irina A. Pobozheva ${ }^{1,2}$, Aleksandra A. Panteleeva ${ }^{1,2}$, \\ Natalia D. Razgildina ${ }^{2}$, Diana A. Kolodina ${ }^{1}$, Olga D. Belyaeva ${ }^{1}$, Olga A. Berkovich ${ }^{1}$, Sofya N. Pchelina ${ }^{1,2}$ \\ and Elena I. Baranova ${ }^{1}$

\begin{abstract}
${ }^{1}$ Pavlov First Saint Petersburg State Medical University, St.-Petersburg, Russian Federation. ${ }^{2}$ National Research Center Kurchatov Institute, Petersburg Nuclear Physics Institute, Gatchina, Russian Federation.
\end{abstract}

\begin{abstract}
Omentin-1 and fatty acid-binding protein 4 (FABP4) are adipose tissue adipokines linked to obesity-associated cardiovascular complications. The aim of this study was to investigate epicardial adipose tissue (EAT) omentin-1 and FABP4 gene expression in obese and non-obese patients with coronary artery disease (CAD). Omentin-1 and FABP4 mRNA levels in EAT and paired subcutaneous adipose tissue (SAT) as well as adipokine serum concentrations were assessed in 77 individuals (61 with CAD; 16 without CAD (NCAD)). EAT FABP4 mRNA level was decreased in obese CAD patients when compared to obese NCAD individuals $(p=0.001)$. SAT FABP4 mRNA level was decreased in CAD patients compared to NCAD individuals without respect to their obesity status $(\mathrm{p}=0.001)$. Omentin-1 mRNA level in EAT and SAT did not differ between the CAD and NCAD groups. These findings suggest that omentin-1 gene expression in adipose tissue is not changed during CAD; downregulated FABP4 gene expression in SAT is associated with CAD while EAT FABP4 gene expression is decreased only in obesity-related CAD.
\end{abstract}

Keywords: Coronary artery disease, epicardial adipose tissue, subcutaneous adipose tissue, FABP4, omentin-1.

Received: November 28, 2020; Accepted: July 10, 2021.

\section{Introduction}

Adipose tissue produces adipokines, and any abnormality in their expression and secretion can play a role in the development of obesity-associated diseases (Ntaios et al., 2013; Lau et al., 2017). Previous studies have proposed the imbalance in adipokine secretion in obesity, metabolic syndrome, diabetes, hypertension, atherosclerosis and cardiovascular disease (Lau et al., 2017). Visceral obesity is generally accompanied by an excess volume of epicardial adipose tissue (EAT), a special visceral fat depot with local and systemic effects. EAT surrounds the heart and is in direct contact with the coronary arteries (Fernández-Trasancos et al., 2017). As EAT adipokines can influence the coronary circulation via paracrine and vasocrine mechanisms, EAT may participate in the development of atherosclerosis (Takaoka et al., 2009; Iacobellis, 2015). EAT volume is associated with atherosclerotic lesions in the coronary arteries and severity of CAD, as well as fatal and nonfatal coronary events in the general population, regardless of the presence of traditional risk factors of cardiovascular disease, such as smoking, obesity, dyslipidemia and diabetes mellitus (Iacobellis, 2015).

EAT has a unique transcriptome enriched with genes related to inflammation and endothelial dysfunction and may be closely associated with atherosclerosis initiation and

Send correspondence to Valentina Miroshnikova. Pavlov First Saint Petersburg State Medical University, L'va Tolstogo str. 6-8 building 28, 197022, St.-Petersburg, Russian Federation.

E-mail: miroshnikova_vv@pnpi.nrcki.ru. progression (Iacobellis, 2015). Patients with CAD exhibit a pronounced pro-inflammatory gene expression profile of EAT as compared with individuals without CAD (Mazurek et al., 2003; Cheng et al., 2008; Sacks et al., 2011). Considered as pro-inflammatory adipocytokine fatty acid binding protein 4 (FABP4) is locally produced by both EAT and macrophages in vascular plaques and may promote development of coronary atherosclerosis (Lee et al., 2013; Furuhashi et al., 2016). FABP4 is a member of the lipid chaperone family and regulates the intracellular transport of fatty acids (Rodríguez-Calvo et al., 2017). Prospective trials have shown that FABP4 plasma level is associated with the development of metabolic syndrome and type 2 diabetes mellitus and predicts cardiovascular events (Xu et al., 2007; Ohyama et al., 2013; Rodríguez-Calvo et al., 2017; Höbaus et al., 2018). In addition, plasma level of FABP4 is related to elevated cardiovascular mortality in male patients with type 2 diabetes mellitus (Xu et al., 2007; Rodríguez-Calvo et al., 2017).

Among anti-inflammatory and anti-atherogenic adipocytokines, omentin-1, also named intelectin-1, is known to be highly expressed in EAT (Fain et al., 2008; Gaborit et al., 2015). Serum concentration of omentin-1 is decreased in obese patients, and this phenomenon is considered to be related to insulin resistance (de Souza Batista et al., 2007). Although studies investigating the link between omentin-1 and cardiovascular outcomes, provided contradictory results, a meta-analysis demonstrated the independent and negative association between omentin-1 serum concentration and CAD (Narumi et al., 2014; Agasthi et al., 2015; Menzel et al., 2016; Saely et al., 2016; Zhou et al., 2017; Xu et al., 2018). 
Omentin-1 supplementation and pharmacological inhibition of FABP4 were shown to reduce atherosclerotic plaque formation in an apolipoprotein E (ApoE)-deficient animal model of atherosclerosis (Fernández-Trasancos et al., 2017; Rodríguez-Calvo et al., 2017). It is hypothesized that omentin-1 and FABP4 gene expression in EAT may influence CAD development. In the present study we investigated omentin-1 and FABP4 gene expression in EAT and paired subcutaneous adipose tissue (SAT) samples of patients with CAD and individuals without CAD (NCAD) with or without abdominal obesity.

\section{Subjects and Methods}

\section{Subjects}

The study enrolled 77 patients who underwent cardiac surgery. Coronary angiography was performed in all participants to detect coronary atherosclerosis and prove CAD. Patients were divided into two groups: CAD patients who underwent coronary artery bypass grafting $(n=61)$ or NCAD subjects $(\mathrm{n}=16$; control group). Principal criteria for inclusion to the CAD group: 1-2-3-vessel coronary obstruction demonstrated by coronary angiography. Gensini Score was used as a tool for measuring coronary atherosclerosis severity, every atherosclerotic narrowing from $25 \%$ to $100 \%$ was included in the calculation multiplied by appropriate Gensini ratio depending on segment location and importance (Gensini, 1983; Neeland et al., 2012). The NCAD group included patients undergoing open-heart surgery for valvular replacement without stenosis in coronary artery lumen. Clinical characteristics, including demographic data, body weight, height, waist circumference, medical history and medication use, were obtained from the hospital records. Body mass index (BMI) was calculated as weight $(\mathrm{kg})$ divided by square of height $\left(\mathrm{m}^{2}\right)$. Main exclusion criteria were as follows: cancer, chronic obstructive pulmonary disease, liver or renal failure, connective tissue diseases, acute rheumatic fever, infective endocarditis, hypo/hyperthyroidism, brain diseases, alcohol or drug abuse, acute cerebrovascular accident. EAT thickness was measured by echocardiography using GE VIVID 7 Dimension cardiovascular ultrasound system, in front of the right ventricle wall from the parasternal long axis view.

The study protocol corresponds to the Helsinki Declaration and was approved by the ethics committee of Pavlov First Saint-Petersburg State Medical University, St.Petersburg, Russian Federation. Written informed consent was obtained from each patient before enrollment.

\section{Blood sample measurements}

Fasting venous blood samples were collected in sodium heparin Vacutainers (Becton-Dickinson), and centrifuged for $15 \mathrm{~min}$ at $3000 \times \mathrm{g}$. The serum samples were then stored -80 ${ }^{\circ} \mathrm{C}$. Biochemical parameters, including baseline levels of fasting glucose and lipids, were measured, and concentrations of serum omentin-1 and FABP-4 were detected using commercially available enzyme-linked immunosorbent assay kits (RayBiotech, USA, and BioVendor, Czech Republic, respectively) following the manufacturer's instructions. All samples were measured in triplicates.

\section{Adipose tissue samples}

Paired adipose tissue samples were collected by biopsy from approximately the same location in all patients, including EAT (near right coronary artery ostium) and SAT (from the area of chest incision). Tissue samples (average $0.1 \mathrm{~g}$ ) were separated from any attached connective tissue and blood vessels and stored at $-80^{\circ} \mathrm{C}$ for further RNA extraction.

\section{RNA isolation and quantitative PCR}

Total RNA was extracted from samples using RNeasy kit (Qiagen) and its concentration and purity were assessed by calculating the ratio of optical density at 260 and 280 nm wavelengths (OD 260/280). The integrity of RNA was assessed using non-denaturing $1 \%$ agarose gel electrophoresis and reflected by the $18 \mathrm{~S}$ and $28 \mathrm{~S}$ ribosomal bands. In brief, $2 \mu \mathrm{g}$ of RNA from each biopsy was reverse transcribed with RevertAid First Strand cDNA Synthesis kit (Thermo Fisher Scientific, USA) according to the instructions in the manual. Quantitative real-time PCR analysis was conducted using the CFX96 Real-Time PCR Detection System (Bio-Rad, USA). Each reaction contained $1 \mu \mathrm{L}$ of resultant cDNA, 0.5 $\mu \mathrm{L}$ of each primer $(10 \mu \mathrm{mol} / \mathrm{L}), 0.8 \mu \mathrm{L}$ of TaqMan probes $(10 \mu \mathrm{mol} / \mathrm{L}), 8 \mu \mathrm{L}$ of sterile water and $10 \mu \mathrm{L}$ of Master Mix (Thermo Fisher Scientific, USA). Amplification was performed as follows: $3 \mathrm{~min}$ at $95^{\circ} \mathrm{C}$, followed by 45 cycles of $15 \mathrm{~s}$ at $95{ }^{\circ} \mathrm{C}, 15 \mathrm{~s}$ at $58^{\circ} \mathrm{C}, 15 \mathrm{~s}$ at $72{ }^{\circ} \mathrm{C}$. The experiment was run for three biological replicates.

The primers sequences used were as follows: omentin-1, forward 5'-aac-gcc-ttg-tgt-gct-gga-at-3', reverse 5'-gta-tcc-tcctcc-acc-aat-gca-3', probe 5' -(FAM)-tca-ccg-gat-gta-aca-ctg-ag(BHQ1)-3'; FABP4, forward 5'-gta-cct-gga-aac-ttg-tct-cca-3', reverse 5'-cat-gcc-agc-cac-ttt-cct-g-3', probe 5'-(FAM)-agaagt-agg-agt-ggg-ctt-tgc-(BHQ1)-3'; RPLP0, forward 5'-gatcag-gga-cat-gtt-gct-gg- $3^{\prime}$, reverse $5^{\prime}$-gac-ttc-aca-tgg-ggc-aatgg-3', probe 5'-(ROX)-caa-taa-ggt-gcc-agc-tgc-tgc-(RTQ2)-3'; $A C T B$, forward 5'-cgt-gct-gct-gac-cga-gg-3', reverse 5'-acagcc-tgg-ata-gca-acg-tac-a-3', probe $5^{\prime}$-(R6G)-cca-acc-gcgaga-aga-tga-ccc-aga-t-(BHQ1)-3'. Threshold cycle $(\mathrm{Ct})$ values were obtained and relative gene expression was calculated normalizing to two reference genes ( $R P L P 0, A C T B)$ using the formula according to Vandesompele et al. (2002).

\section{Statistical analysis}

Data with normal distribution were expressed as mean $\pm \mathrm{SD}$, otherwise as median (lower quartile, upper quartile). Mean values were compared by the Student's $t$ test, while median values were compared using the Mann-Whitney $U$ test. Categorical variables were expressed as percentages and analyzed by a Chi square test. Spearman correlation analysis was performed between mRNA levels and serum concentrations of adipokines and other biochemical markers as well as waist circumference and BMI. In the CAD group extended multivariate linear regression analysis was employed to evaluate relationship between adipokines serum concentration and gene expression level with the following variables: age, gender, waist circumference (as a marker of abdominal obesity), Gensini score, EAT thickness and statin treatment. Covariates were selected on the basis of clinical relevance. In entire cohort variables that explained the largest 
variability in the patient group and CAD diagnosis as additional factor were analyzed. Statistical analyses were carried out using SPSS 17.0 software (SPSS Inc., Chicago, IL, USA) and $\mathrm{R}$ Studio, with $\mathrm{p}<0.05$ considered as significant.

\section{Results}

\section{Clinical and biochemical characteristics of the studied groups}

Selected clinical and biochemical characteristics of the patients included in this study are summarized in Table 1. Patients with CAD and the representatives of the NCAD group were distributed into subgroups based on the presence of abdominal (central) obesity, thereby dedicating subgroups at increased risk of cardiovascular events for additional analysis. Abdominal obesity was defined as a waist circumference of $\geq 102 \mathrm{~cm}$ for men and $\geq 88 \mathrm{~cm}$ for women according to the American Heart Association/National Heart, Lung, and Blood Institute definition (National Heart, Lung, and Blood Institute, 1998). Overall, the prevalence of abdominal obesity was $51 \%$ in the CAD group and $44 \%$ in the NCAD group. Lipid levels did not differ between subgroups except serum triglyceride concentration that was higher in obese $\mathrm{CAD}$ patients compared to non-obese $\mathrm{CAD}$ patients.

\section{FABP4 gene expression in EAT and SAT}

FABP4 mRNA level in SAT was higher than in EAT, and the difference was more pronounced in obese individuals $(\mathrm{p}=0.001)$ (Figure 1B). SAT FABP4 mRNA level was lower in CAD patients compared to NCAD individuals in both obese and non-obese subgroups (Figure 1C). EAT FABP4 mRNA level was reduced only in CAD patients with central obesity as compared with that in the corresponding NCAD individuals (Figure 1D). However, the FABP4 serum concentration did not differ between subgroups (Figure 1A). No association was shown between FABP4 serum concentration and FABP4 gene expression in adipose tissue. Multivariate regression analysis has shown that FABP4 serum concentrations in CAD patients were strongly predicted by age, sex and waist circumference not by gene expression (Table S1). However, CAD diagnosis was significant predictor for FABP4 gene expression in SAT independently of age, sex and adiposity (Table S1).

\section{Omentin-1 gene expression in EAT and SAT}

Omentin-1 mRNA level in EAT was markedly increased compared with that in SAT $(\mathrm{p}=0.001)$ (Figure $2 \mathrm{~B})$. However, no difference in omentin-1 mRNA level was observed in EAT and SAT between CAD and NCAD patients neither in united groups no in subgroups based on obesity status

Table 1 - Clinical and biochemical characteristics of the studied groups with detailed medications.

\begin{tabular}{|c|c|c|c|c|}
\hline & \multicolumn{2}{|c|}{$\begin{array}{c}\text { CAD patients } \\
\quad \mathrm{N}=61\end{array}$} & \multicolumn{2}{|c|}{$\begin{array}{l}\text { NCAD patients } \\
\text { (Control group) } \\
\mathrm{N}=16\end{array}$} \\
\hline & $\begin{array}{l}\text { Obese } \\
\mathrm{N}=31\end{array}$ & $\begin{array}{c}\text { Non-obese } \\
\mathrm{N}=30\end{array}$ & $\begin{array}{c}\text { Obese } \\
\mathrm{N}=7\end{array}$ & $\begin{array}{c}\text { Non-obese } \\
\mathrm{N}=9\end{array}$ \\
\hline Age, years & $60.6 \pm 9.1$ & $61.7 \pm 8.1$ & $67.0 \pm 3.5$ & $55.8 \pm 15.8$ \\
\hline Male/female & $17 / 14$ & $24 / 6$ & $1 / 6$ & $7 / 2$ \\
\hline \multirow{2}{*}{ Waist circumference, $\mathrm{cm}$} & Males: $111(103-120)^{\S}$ & Males: $94(81-101)^{\#}$ & Male: 103 & Males: 83 (69-100) \\
\hline & Females: $95(91-113)^{\S}$ & Females: 82 (79-85) & Females: 96 (91-104) & Females: 63.5 (58-69) \\
\hline BMI, kg/m2 & $31.4 \pm 4.5^{*}$ & $25.9 \pm 2.7$ & $28.8 \pm 4.1$ & $26.7 \pm 9.8$ \\
\hline EAT thickness, mm & $5.3 \pm 1.9 * \#$ & $7.2 \pm 2.6$ & $6.2 \pm 1.4$ & $5.2 \pm 2.0$ \\
\hline Gensini Score & $74(38-148)$ & $71(10-202)$ & - & - \\
\hline Triglyceride, $\mathrm{mmol} / \mathrm{L}$ & $1.98 \pm 1.03 *$ & $1.41 \pm 0.57$ & $1.86 \pm 1.14$ & $1.01 \pm 0.48$ \\
\hline Total cholesterol, $\mathrm{mmol} / \mathrm{L}$ & $4.43 \pm 1.27 *$ & $5.21 \pm 1.76$ & $5.02 \pm 0.88$ & $4.23 \pm 1.02$ \\
\hline HDL-cholesterol, mmol/L & $1.32 \pm 0.32$ & $1.25 \pm 0.33$ & $1.22 \pm 0.22$ & $1.17 \pm 0.48$ \\
\hline LDL-cholesterol, mmol/L & $2.17 \pm 1.06^{*}$ & $3.14 \pm 1.28$ & $2.94 \pm 0.44$ & $2.73 \pm 0.63$ \\
\hline Fasting glucose, $\mathrm{mmol} / \mathrm{L}$ & $5.95 \pm 0.79$ & $5.49 \pm 0.92$ & $5.60 \pm 1.44$ & $5.41 \pm 1.41$ \\
\hline \multicolumn{5}{|l|}{ Medications, N (\%) } \\
\hline Statins & $19(61 \%)$ & $16(53 \%)$ & $1(14 \%)$ & $1(11 \%)$ \\
\hline Aspirin & $18(58 \%)$ & $18(60 \%)$ & $0(0 \%)$ & $0(0 \%)$ \\
\hline Nitrates & $9(29 \%)$ & $10(33 \%)$ & $0(0 \%)$ & $0(0 \%)$ \\
\hline ACEI/ARB & $5(16 \%)$ & $4(13 \%)$ & $0(0 \%)$ & $0(0 \%)$ \\
\hline Beta-blockers & $22(71 \%)$ & $25(83 \%)$ & $1(14 \%)$ & $2(22 \%)$ \\
\hline Calcium channel blockers & $6(19 \%)$ & $7(23 \%)$ & $0(0 \%)$ & $0(0 \%)$ \\
\hline
\end{tabular}

* $\mathrm{p}<0.05$, obese CAD vs non-obese CAD patients. ${ }^{*} \mathrm{p}<0.05$, non-obese CAD vs non-obese NCAD. ${ }^{\S} \mathrm{p}<0.01$, obese CAD vs non-obese CAD patients. Abbreviations: ACEI/ARB an angiotensin-converting enzyme inhibitors/ an angiotensin receptor blockers, BMI body mass index, CAD coronary artery disease, EAT epicardial adipose tissue, HDL high density lipoproteins, LDL low density lipoproteins. 
A

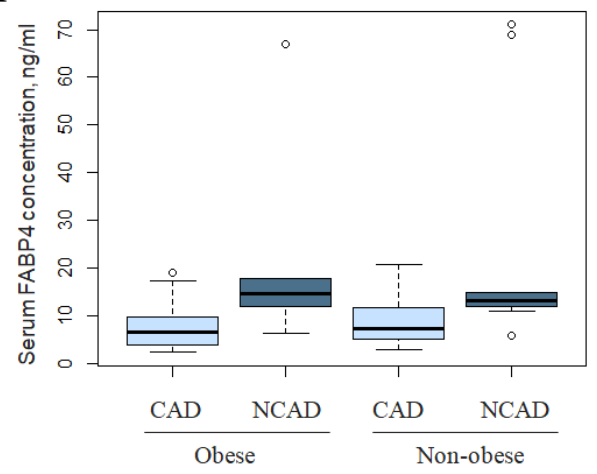

C

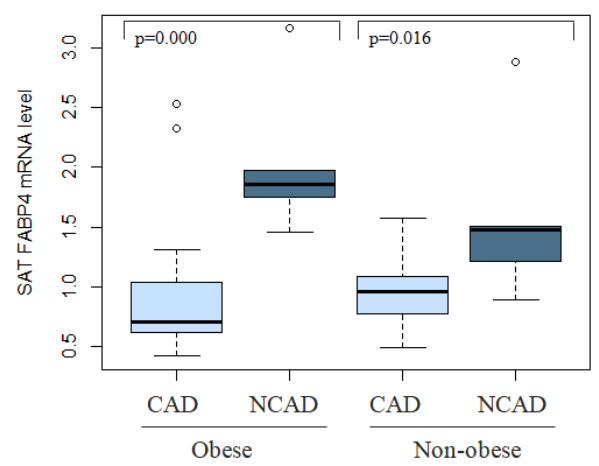

B

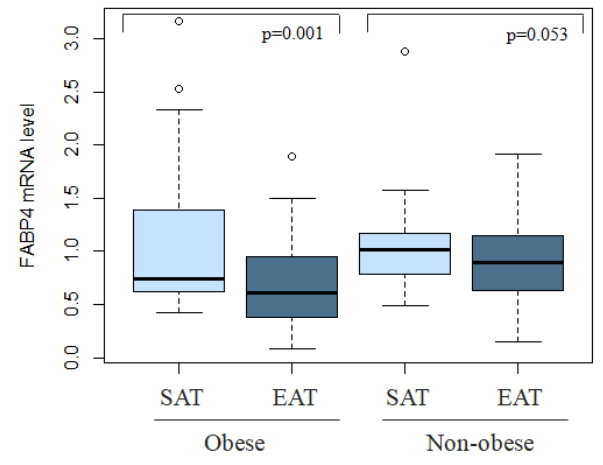

$\mathrm{D}$

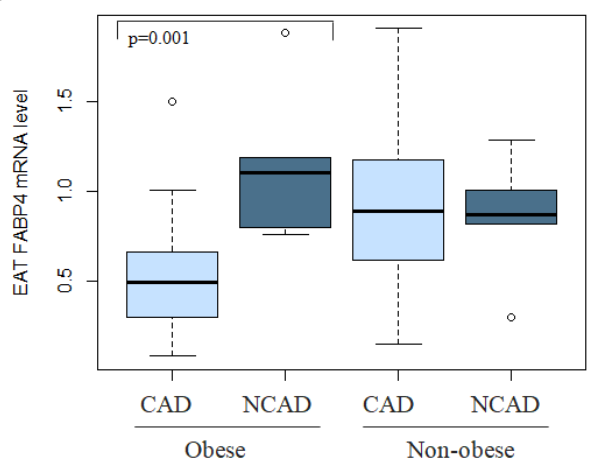

Figure 1 - FABP4 serum concentration (A) and gene expression in adipose tissue in obese and non-obese subgroups: comparative analysis of the $F A B P 4$ gene expression in subcutaneous and epicardial fat depots (B); FABP4 mRNA level in subcutaneous (C) and epicardial adipose tissue (D) in CAD and NCAD individuals.

A

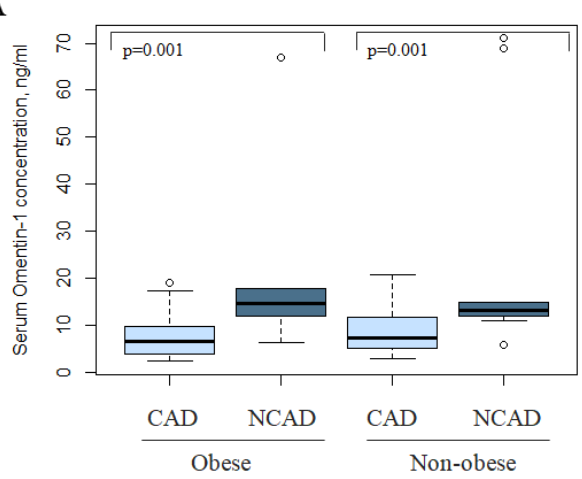

C

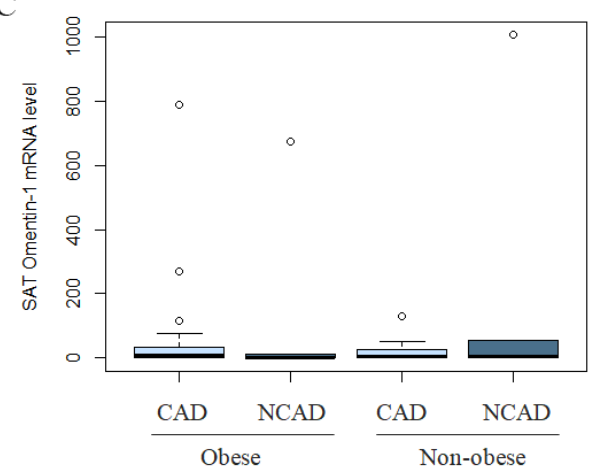

B

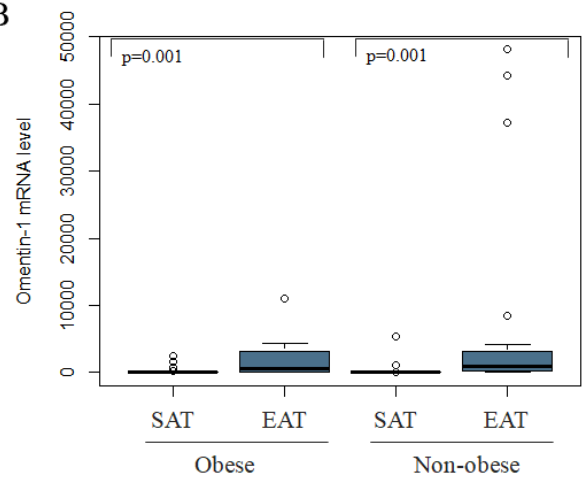

D

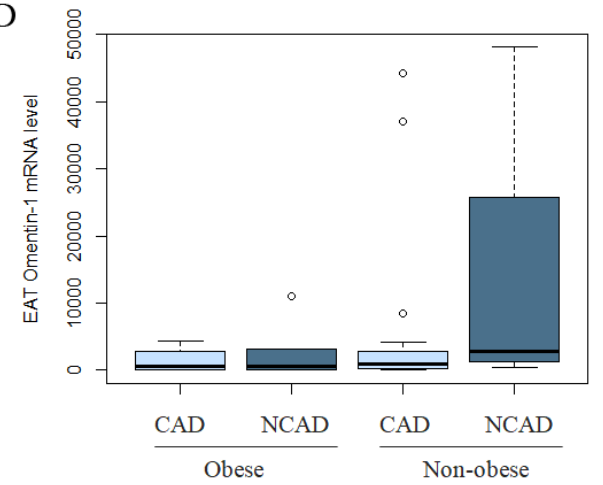

Figure 2 - Omentin-1 serum concentration (A) and gene expression in adipose tissue in obese and non-obese subgroups: comparative analysis of the omentin-1 gene expression in subcutaneous and epicardial fat depots (B); omentin-1 mRNA level in subcutaneous (C) and epicardial adipose tissue (D) in CAD and NCAD individuals. 
(Figure 2C, D). Neither EAT or SAT omentin-1 mRNA level showed any correlation with omentin- 1 serum concentration. At the same time omentin-1 serum concentration was lower in the CAD group than in the NCAD group $(\mathrm{p}=0.001)$ (Figure $2 \mathrm{~A})$.

Omentin-1 serum concentration and mRNA level in EAT were inversely correlated with waist circumference $(\mathrm{r}=-0.426, \mathrm{p}=0.002$ and $\mathrm{r}=-0.368, \mathrm{p}=0.013$, respectively) and $\operatorname{BMI}(\mathrm{r}=-0.364, \mathrm{p}=0.003$ and $\mathrm{r}=-0.364, \mathrm{p}=0.015$, respectively). Multivariate regression analysis has shown significant correlation only between omentin-1 serum concentration and waist circumference upon adjustment for age, sex and EAT thickness $(\beta=-0,385, p=0,011$ for the CAD group; $\beta=-$ $0,446, p=0,000$ for the entire cohort; Table S2). Omentin-1 serum concentration was predicted by CAD diagnosis as well as gender and waist circumference (Table S2).

\section{Discussion}

In the present study, we show that FABP4 mRNA expression was downregulated in SAT of patients with CAD. At the same time, FABP 4 mRNA level in EAT was decreased only in obese CAD patients. This finding was unexpected as FABP4 is considered as a pro-inflammatory adipocytokine (Rodríguez-Calvo et al., 2017). Studies have shown that increased FABP4 plasma levels predict development of metabolic syndrome and type 2 diabetes mellitus, as well as cardiovascular events in patients with peripheral arterial disease (Xu et al., 2007; Ohyama et al., 2013; Höbaus et al., 2018; Rodríguez-Calvo et al., 2017). Clinical data and the findings from a FABP4-null mouse study confirmed the role of FABP4 as a key factor involved in the development of obesity-related pathologies in humans (Xu et al., 2007).

FABP4 is known to be expressed by the macrophages in adipose tissue as well as those from atherosclerotic plaques (Agardh et al., 2011; Furuhashi et al., 2016). FABP4 was shown to be secreted by macrophages cultured in vitro (Furuhashi et al., 2016). The potential impact of FABP4 on atherosclerosis may be mainly due to value of this molecule in macrophages rather than in adipocytes, as was demonstrated by studies involving bone marrow transplantation (Rodríguez-Calvo et al., 2017). Thus, FABP4 locally produced by macrophages from EAT and carotid plaques could contribute to CAD development and progression (Agardh et al., 2011; Furuhashi et al., 2016).

There are only few studies assessing FABP4 expression level in EAT of CAD patients, with limited sample size ranging from 10 to 16 patients (Vural et al., 2008; Sacks et al., 2011). In contrast to our data, Vural and colleagues demonstrated higher FABP4 mRNA levels in EAT and ascending aorta of CAD patients with metabolic syndrome compared with metabolically healthy individuals (Vural et al., 2008). Ten CAD patients with metabolic syndrome and four controls without metabolic syndrome, who underwent cardiac valvular repair due to aortic stenosis, were examined in their study. Sacks et al. also reported increased FABP 4 mRNA levels in EAT and SAT of 16 patients with severe stable CAD who were overweight as compared to 12 controls (Sacks et al., 2011). It should be noted that these results should be interpreted with caution as hypoglycemic drugs and statins were shown to reduce FABP4 serum concentration and $F A B P 4$ gene expression (Llaverias et al., 2004; Song et al., 2010; Hu et al., 2012; Furuhashi et al.,
2015). Furthermore, FABP4 serum and adipose tissue level could be modulated by obesity; hence, we analyzed patients with central obesity and potential metabolic complications separately from non-obese patients. Majority of CAD patients in our study were prescribed statins. Therefore, FABP4 mRNA reduction in SAT of CAD patients and in EAT of only obese CAD patients may be a consequence of high dose statin treatment. In particular, FABP4 mRNA was downregulated in EAT of obese CAD patients, consistent with the significant decrease in total and LDL cholesterol levels in this cohort. Intensive treatment may also be the cause of decreased EAT thickness in obese CAD patients (Parisi et al., 2019; Raggi et al., 2019). Additionally, our results are in agreement with the data of a recent proteomic analysis that showed FABP4 down regulation in EAT of CAD patients (Zhao et al., 2019).

Regarding FABP4 expression and secretion activity of different fat depots, FABP4 expression was found to be similar in SAT and visceral adipose tissue (VAT) of lean subjects but higher in SAT than in VAT of obese individuals (Fisher et al., 2002; Terra et al., 2011). EAT is a type of VAT but with specific properties. In our study, FABP 4 mRNA level was higher in SAT than in EAT and this difference was more pronounced in obese individuals.

At the same time it was shown earlier that SAT and VAT FABP4 gene expression level did not differ between normally weighing and metabolically healthy obese individuals (Garin-Shkolnik et al., 2014; Grzegorczyk et al., 2018). However, contradictory results have been published with respect to FABP4 gene expression in patients with metabolic complications and diabetes. Adipose tissue expression of the FABP4 gene was shown to be increased in morbidly obese individuals and patients with diabetes, assuming the role of adipose FABP4 in the pathogenesis of insulin resistance and metabolic syndrome (Terra et al., 2011; Garin-Shkolnik et al., 2014). On the contrary, in the study of Queipo-Ortuño and colleagues lean subjects had significantly higher FABP4 mRNA levels in SAT than overweight, obese and morbidly obese subjects (Queipo-Ortuño et al., 2012). For morbidly obese subjects a down-regulation of FABP 4 mRNA in VAT was demonstrated, mainly in insulin-resistant patients (QueipoOrtuño et al., 2012). FABP4 plasma levels progressively increased with BMI but without any association with FABP4 gene expression in adipose tissue (Queipo-Ortuño et al., 2012).

Apart from well-known value as an adiposity biomarker (Rodríguez-Calvo et al., 2017), elevated FABP4 serum concentration on the background of obesity and metabolic syndrome could be also due to it's high expression in the liver. Hepatic FABP4 gene expression is increased while adipose tissue expression is decreased in obese mice compared to wild type mice (Queipo-Ortuño et al., 2012; Thompson et al., 2018). Hepatic expression of the FABP 1, FABP 4 and FABP5 genes was shown to be significantly upregulated in morbidly obese patients with insulin resistance (Queipo-Ortuño et al., 2012). Elevated FABP4 serum concentrations and higher gene expression in the liver were reported in patients with hepatic pathology (Graupera et al., 2017; Thompson et al., 2018). These facts indicate that adipose tissue gene expression could not fully predict FABP4 serum concentration in obese patients with metabolic complications what we also show in our study. 
In the present study, omentin-1 serum concentrations were decreased in CAD patients. Previous meta-analyses demonstrated that serum omentin-1 concentration was independently and negatively associated with CAD and reduced in obese individuals (Agasthi et al., 2015; Arab et al., 2020). Researchers who performed studies on patients with type 2 diabetes mellitus suggest that decreased omentin-1 level may be an independent risk factor for arteriosclerosis and carotid plaque formation in these patients (Yoo et al., 2011; Nishimura et al., 2019; Biscetti et al., 2020). Low omentin-1 serum concentration was associated with acute coronary syndrome, stable angina and ischemic stroke (Shibata et al., 2011; Zhong et al., 2011; Yue et al., 2018). Other investigators reported that elevated omentin-1 plasma level predicts cardiovascular events (Menzel et al., 2016; Saely et al., 2016). At the same time in vitro studies of exogenous omentin-1 expression proved the cardioprotective functions of omentin-1: omentin-1 improved insulin sensitivity and anti-inflammatory activity of cultured EAT and SAT tissue samples of patients with cardiovascular disease and reduced atherosclerotic plaque formation in an ApoE-deficient animal model of atherosclerosis (Hiramatsu-Ito et al., 2016; Fernández-Trasancos et al., 2017).

Contradictory results have been published earlier on the omentin-1 gene expression in EAT of patients with CAD. While Harada and colleagues showed that omentin-1 gene expression was upregulated in CAD patients, $\mathrm{Du}$ and colleagues demonstrated decreased omentin-1 gene expression in EAT of CAD patients (Du et al., 2016; Harada et al., 2016). Both studies were conducted with limited sample sizes and didn't include overweight CAD patients and controls. In our study we included a larger number of patients with CAD and without CAD (NCAD) with normal body weight or with obesity. We demonstrated that omentin-1 mRNA levels in EAT and SAT did not differ significantly between CAD and NCAD groups including when compared separately in subgroups based on obesity status. These findings point out that omentin-1 gene expression in EAT and SAT is not associated with CAD.

We also confirm that omentin-1 expression is upregulated in EAT as compared with SAT, as previously demonstrated (Fain et al., 2008, Gaborit et al., 2015). Summarizing our results, we conclude that SAT may be inactive in omentin-1 secretion. Omentin-1 predominantly is synthesized by VAT, not by SAT, and is highly expressed in epicardial fat (de Souza Batista et al., 2007; Fain et al., 2008, Gaborit et al., 2015). As omentin-1 is secreted by VAT, most of circulating omentin-1 may be of omental fat origin. We can conclude EAT and SAT gene expression could have no significant effect on omentin-1 serum level.

In conclusion, our study demonstrated reduced omentin-1 serum concentrations in patients with CAD. Thus we confirm the protective role of serum omentin-1 demonstrated in previous studies. We also highlight that FABP4 gene expression in SAT is reduced in CAD patients and proposed that decreased EAT and SAT FABP 4 mRNA levels could be associated with CAD development in obese individuals or statin treatment.

There are several limitations to this study: limited sample size of the control group; gender differences of degree of obesity in the studied groups; additionally the drug usage effect in CAD patients could not be excluded. Further prospective studies are needed to evaluate whether FABP4 mRNA levels in EAT and SAT could be used as predictors of CAD development.

\section{Acknowledgements}

The authors thank Drs. Galina V. Alexejeva MD, PhD; Prof. Alexandr S. Nemkov, MD, PhD; Dmitrij V. Maslevtsov, $\mathrm{MD}, \mathrm{PhD}$; Vladimir I. Gavrilenkov, MD, PhD and Olga V. Galkina from Pavlov First Saint Petersburg State Medical University, St.-Petersburg, Russian Federation. This work was supported by Russian foundation for basic research [RFBR $\left.\mathrm{N}^{\mathrm{o}} 18-315-00382\right]$

\section{Conflict of Interest}

The authors declare that they have no conflicts of interest.

\section{Author Contributions}

EB, SP, OBer and OBel conceived the study and performed final interpretation of the data, VM and EP proceeded the methodology, VM, IP, AP and NR conducted gene expression experiments, EP and DK assessed adipokine serum levels and clinical data, VM, EP and IP analyzed the data, VM and IP wrote the first draft of the manuscript, all authors read and approved the final version.

\section{References}

Agardh HE, Folkersen L, Ekstrand J, Marcus D, Swedenborg J, Hedin U, Gabrielsen A and Paulsson-Berne G (2011) Expression of fatty acid-binding protein $4 / \mathrm{aP} 2$ is correlated with plaque instability in carotid atherosclerosis. J Intern Med 269:200-210.

Agasthi P, Aloor S, Axiyan M and Onwuanyi A (2015) Association between serum omentin-1 level and coronary artery disease: a metaanalysis. Arterioscler Thromb Vasc Biol 35:A548.

Arab A, Moosavian SP, Hadi A, Karimi E and Nasirian M (2020) The association between serum omentin level and bodyweight: A systematic review and meta-analysis of observational studies. Clinical Nutrition ESPEN 39:22-29.

Biscetti F, Nardella E, Rando MM, Cecchini AL, Angelini F, Cina A, Iezzi R, Filipponi M, Santoliquido A, Pitocco D et al. (2020) Association between omentin-1 and major cardiovascular events after lower extremity endovascular revascularization in diabetic patients: a prospective cohort study. Cardiovasc Diabetol 19:170.

Cheng KH, Chu CS, Lee KT, Lin TH, Hsieh CC, Chiu CC, Voon WC, Sheu SH and Lai WT (2008) Adipocytokines and proinflammatory mediators from abdominal and epicardial adipose tissue in patients with coronary artery disease. Int $\mathrm{J}$ Obes (Lond) 32:268-74.

De Souza Batista CM, Yang RZ, Lee MJ, Glynn NM, Yu DZ, Pray J, Ndubuizu K, Patil S, Schwartz A, Kligman M et al. (2007) Omentin plasma levels and gene expression are decreased in obesity. Diabetes 56:1655-1661.

Du Y, Ji Q, Cai L, Huang F, Lai Y, Liu Y, Yu J, Han B, Zhu E, Zhang $\mathrm{J}$ et al. (2016) Association between omentin-1 expression in human epicardial adipose tissue and coronary atherosclerosis. Cardiovasc Diabetol 15:90.

Fain JN, Sacks HS, Buehrer B, Bahouth SW, Garrett E, Wolf RY, Carter RA, Tichansky DS and Madan AK (2008) Identification of omentin mRNA in human epicardial adipose tissue: comparison to omentin in subcutaneous, internal mammary artery periadventitial and visceral abdominal depots. Int $\mathrm{J}$ Obes (Lond) 32:810-815. 
Fernández-Trasancos Á, Agra RM, García-Acuña JM, Fernández ÁL, González-Juanatey JR and Eiras S (2017) Omentin treatment of epicardial fat improves its anti-inflammatory activity and paracrine benefit on smooth muscle cells. Obesity (Silver Spring) 25:1042-1049.

Fisher RM, Thörne A, Hamsten A and Arner P (2002) Fatty acid binding protein expression in different human adipose tissue depots in relation to rates of lipolysis and insulin concentration in obese individuals. Mol Cell Biochem 239:95-100.

Furuhashi M, Hiramitsu S, Mita T, Fuseya T, Ishimura S, Omori A, Matsumoto M, Watanabe Y, Hoshina K, Tanaka M et al. (2015) Reduction of serum FABP4 level by sitagliptin, a DPP-4 inhibitor, in patients with type 2 diabetes mellitus. J Lipid Res 56:2372-2380.

Furuhashi M, Fuseya T, Murata M, Hoshina K, Ishimura S, Mita $\mathrm{T}$, Watanabe Y, Omori A, Matsumoto M, Sugaya T et al. (2016) Local production of fatty acid-binding protein 4 in epicardial/perivascular fat and macrophages is linked to coronary atherosclerosis. Arterioscler Thromb Vasc Biol 36:825-34.

Gaborit B, Venteclef N, Ancel P, Pelloux V, Gariboldi V, Leprince P, Amour J, Natem SN, Jouve E, Dutour A et al. (2015) Human epicardial adipose tissue has a specific transcriptomic signature depending on its anatomical peri-atrial, peri-ventricular, or peri-coronary location. Cardiovasc Res 108:62-73.

Garin-Shkolnik T, Rudich A, Hotamisligil GS and Rubinstein M (2014) FABP4 attenuates PPAR $\gamma$ and adipogenesis and is inversely correlated with PPAR $\gamma$ in adipose tissues. Diabetes 63:900-911.

Gensini GG (1983) A more meaningful scoring system for determining the severity of coronary heart disease. Am J Cardiol 51:606.

Graupera I, Coll M, Pose E, Elia C, Piano S, Sola E, Blaya D, Huelin P, Sole C, Moreira R et al. (2017) Adipocyte fatty-acid binding protein is overexpressed in cirrhosis and correlates with clinical outcomes. Sci Rep 7:1829.

Grzegorczyk EA, Harasim-Symbor E, Lukaszuk B, Harasiuk D, Choromanska B, Mysliwiec P, Zendzian-Piotrowska M and Chabowski A (2018) Lack of pronounced changes in the expression of fatty acid handling proteins in adipose tissue and plasma of morbidly obese humans. Nutr Diabetes 8:3.

Harada K, Shibata R, Ouchi N, Tokuda Y, Funakubo H, Suzuki M, Kataoka T, Nagao T, Okumura S, Shonoda N et al. (2016) Increased expression of the adipocytokine omentin in the epicardial adipose tissue of coronary artery disease patients. Atherosclerosis 251:299-304.

Hiramatsu-Ito M, Shibata R, Ohashi K, Uemura Y, Kanemura N, Kambara T, Enomoto T, Yuasa D, Matsuo $\mathrm{K}$, Ito $\mathrm{M}$ et al. (2016) Omentin attenuates atherosclerotic lesion formation in apolipoprotein E-deficient mice. Cardiovasc Res 110:107-117.

Höbaus C, Herz CT, Pesau G, Wrba T, Koppensteiner R and Schernthaner GH (2018) FABP4 and cardiovascular events in peripheral arterial disease. Angiology 69:424-430.

Hu W, Zhou X, Jiang M, Duan Y, Chen Y, Li X, Yin Z, He G, Yao Z, Zhu Y et al. (2012) Statins synergize dexamethasone-induced adipocyte fatty acid binding protein expression in macrophages. Atherosclerosis 222:434-43.

Iacobellis G (2015) Local and systemic effects of the multifaceted epicardial adipose tissue depot. Nat Rev Endocrinol 11:363-371.

Lau WB, Ohashi K, Wang Y, Ogawa H, Murohara T, Ma XL and Ouchi N (2017) Role of adipokines in cardiovascular disease. Circ J 81:920-928.

Lee K, Santibanez-Koref M, Polvikoski T, Birchall D, Mendelow AD and Keavney B (2013) Increased expression of fatty acid binding protein 4 and leptin in resident macrophages characterises atherosclerotic plaque rupture. Atherosclerosis 226:74-81.
Llaverias G, Noé V, Peñuelas S, Vázquez-Carrera M, Sánchez RM, Laguna JC, Ciudad CJ and Alegret M (2004) Atorvastatin reduces CD68, FABP4, and HBP expression in oxLDLtreated human macrophages. Biochem Biophys Res Commun 318:265-74.

Mazurek T, Zhang L, Zalewski A, Mannion JD, Diehl JT, Arafat H, Sarov-Blat L, O'Brien S, Keiper EA, Johnson AG et al. (2003) Human epicardial adipose tissue is a source of inflammatory mediators. Circulation 108:2460-2466.

Menzel J, di Giuseppe R, Biemann R, Wittenbecher C, Aleksandrova K, Pischon T, Fritsche A, Schulze MB, Boeing H, Isermann B et al. (2016) Omentin-1 and risk of myocardial infarction and stroke: results from the EPIC-Potsdam cohort study. Atherosclerosis 251:415-421.

Narumi T, Watanabe T, Kadowaki S, Kinoshita D, Yokoyama M, Honda Y, Otaki Y, Nishiyama S, Takahashi H, Arimoto T et al. (2014) Impact of serum omentin-1 levels on cardiac prognosis in patients with heart failure. Cardiovasc Diabetol 13:84.

National Heart, Lung, and Blood Institute (1998) Clinical guidelines on the identification evaluation, and treatment of overweight and obesity in adults. Report 98-4083. NIH, Bethesda, 228 p.

Neeland IJ, Patel RS, Eshtehardi P, Dhawan S, McDaniel MC, Rab ST, Vaccarino V, Zafari AM, Samady H, Quyyumi AA (2012) Coronary angiographic scoring systems: An evaluation of their equivalence and validity. Am Heart J 164:547-552.

Nishimura M, Morioka T, Hayashi M, Kakutani Y, Yamazaki Y, Kurajoh M, Mori K, Fukumoto S, Shioi A, Shoji T et al. (2019) Plasma omentin levels are inversely associated with atherosclerosis in type 2 diabetes patients with increased plasma adiponectin levels: a cross-sectional study. Cardiovasc Diabetol 18:167.

Ntaios G, Gatselis NK, Makaritsis K and Dalekos GN (2013) Adipokines as mediators of endothelial function and atherosclerosis. Atherosclerosis 227:216-221.

Ohyama Y, Iso T, Masuda K, Tamura S, Murata M, Iijima T, Goto K, Funada R, Koitabashi N, Takama N et al. (2013) Serum fatty acid binding protein 4 is an early marker for acute myocardial infarction. J Am Coll Cardiol 61:E191.

Parisi V, Petraglia L, D’Esposito V, Cabaro S, Rengo G, Caruso A, Grimaldi MG, Baldascino F, De Bellis, Vitale D et al. (2019) Statin therapy modulates thickness and inflammatory profile of human epicardial adipose tissue. Int J Cardiol 274:326-330

Queipo-Ortuño MI, Escoté X, Ceperuelo-Mallafré V, GarridoSanchez L, Miranda M, Clemente-Postigo M, Pérez-Pérez R, Peral B, Cardona F, Fernández-Real JM et al. (2012) FABP4 Dynamics in Obesity: Discrepancies in Adipose Tissue and Liver Expression Regarding Circulating Plasma Levels. Plos One 7:e4860

Raggi P, Gadiyaram V, Zhang C, Chen Z, Lopaschuk G, Stillman AE (2019) Statins reduce epicardial adipose tissue attenuation independent of lipid lowering: A potential pleiotropic effect. J Am Heart Assoc 8:e013104

Rodríguez-Calvo R, Girona J, Alegret JM, Bosquet A, Ibarretxe D and Masana L (2017) Role of the fatty acid-binding protein 4 in heart failure and cardiovascular disease. J Endocrinol 233:R173-R184.

Sacks HD, Fain JN, Cheema P, Bahouth SW, Garrett E, Wolf RY, Wolford D and Samaha J (2011) Depot-specific overexpression of proinflammatory, redox, endothelial cell, and angiogenic genes in epicardial fat adjacent to severe stable coronary atherosclerosis. Metab Syndr Relat Disord 9:433-439.

Saely CH, Leiherer A, Muendlein A, Vonbank A, Rein P, Geiger K, Malin C and Drexel H (2016) Coronary patients with high plasma omentin are at a higher cardiovascular risk. Data Brief 6:158-161. 
Shibata R, Ouchi N, Kikuchi R, Takahashi R, Takeshita K, Kataoka Y, Ohashi K, Ikeda N, Kihara S, Murohara T (2011) Circulating omentin is associated with coronary artery disease in men. Atherosclerosis 219:811-814.

Song J, Ren P, Zhang L, Wang XL, Chen L and Shen YH (2010) Metformin reduces lipid accumulation in macrophages by inhibiting FOXO1-mediated transcription of fatty acid-binding protein 4. Biochem Biophys Res Commun 393:89-94.

Takaoka M, Nagata D, Kihara S, Shimomura I, Kimura Y, Tabata Y, Saito Y, Nagai R and Sata M (2009) Periadventitial adipose tissue plays a critical role in vascular remodeling. Circ Res 105:906-911.

Terra X, Quintero Y, Auguet T, Porras JA, Hernández M and Sabench F (2011) FABP4 is associated with inflammatory markers and metabolic syndrome in morbidly obese women. Eur $\mathrm{J}$ Endocrinol 164:539-547.

Thompson KJ, Austin RG, Nazari SS, Gersin KS, Iannitti DA and McKillop IH (2018) Altered fatty acid-binding protein 4 (FABP4) expression and function in human and animal models of hepatocellular carcinoma. Liver Int 38:1074-1083.

Vandesompele J, De Preter K, Pattyn F, Poppe B, Van Roy N, De Paepe A and Speleman F (2002) Accurate normalization of real-time quantitative RT-PCR data by geometric averaging of multiple internal control genes. Genome Biol 3 :research0034.

Vural B, Atalar F, Ciftci C, Demirkan A, Susleyici-Duman B, Gunay D, Akpinar B, Sagbas E, Ozbek U, Buyukdevrim AS (2008) Presence of fatty-acid-binding protein 4 expression in human epicardial adipose tissue in metabolic syndrome. Cardiovasc Pathol 17:392-398.

Xu A, Tso AW, Cheung BM, Wang Y, Wat NM, Fong CH, Yeung DCY, Janus ED, Sham PC and Lam KSL (2007) Circulating adipocytefatty acid binding protein levels predict the development of the metabolic syndrome: a 5-year prospective study. Circulation 115:1537-1543.

Xu T, Zuo P, Wang Y, Gao Z and Ke K (2018) Serum omentin-1 is a novel biomarker for predicting the functional outcome of acute ischemic stroke patients. Clin Chem Lab Med 56:350-355.
Yoo HJ, Hwang SY, Hong HC, Choi HY, Yang SJ, Seo JA, Kim SG, Kim NH, Choi KM, Choi DS et al. (2011) Association of circulating omentin-1 level with arterial stiffness and carotid plaque in type 2 diabetes. Cardiovasc Diabetol 10:103.

Yue J, Chen J, Wu Q, Liu X, Li M, Li Z and Gao Y (2018) Serum levels of omentin-1 association with early diagnosis, lesion volume and severity of acute ischemic stroke. Cytokine 111:518-522.

Zhao YX, Zhu HJ, Pan H, Liu XM, Wang LJ, Yang H, Li N, Gong FY, Sun W and Zeng Y (2019) Comparative proteome analysis of epicardial and subcutaneous adipose tissues from patients with or without coronary artery disease. Int J Endocrinol 2019:6976712

Zhong X, Zhang HY, Tan H, Zhou Y, Liu FL, Chen FQ and Shang D (2011) Association of serum omentin-1 levels with coronary artery disease. Acta Pharmacol Sin 32:873-878.

Zhou JP, Tong XY, Zhu LP, Luo JM, Luo Y, Bai YP, Li CC, Zhang GG (2017) Plasma Omentin-1 Level as a Predictor of Good Coronary Collateral Circulation. J Atheroscler Thromb 24:940948.

\section{Supplementary material}

The following online material is available for this article:

Table S1 - Multiple regression analysis between age, sex, abdominal obesity and FABP4 serum concentration and mRNA level in epicardial and subcutaneous adipose tissue. Table S2 - Multiple regression analysis between age, sex, abdominal obesity and omentin- 1 serum concentration and mRNA level in epicardial and subcutaneous adipose tissue.

Associate Editor: Regina C. Mingroni-Netto

License information:This is an open-access article distributed under the terms of the Creative Commons Attribution License (type CC-BY), which permits unrestricted use, distribution and reproduction in any medium, provided the original article is properly cited. 